\title{
Impacto do Programa de Apoio a Planos de Reestruturação e Expansão das Universidades Federais Brasileiras (REUNI) na atividade investigativa: crescimento, qualidade e internacionalização
}

\author{
Cláudia Daniele de Souza \\ Doutoranda; Universidad Carlos III de Madrid, Madrid, Espanha; \\ csouza@bib.uc3m.es \\ Daniela de Filippo \\ Doutora; Universidad Carlos III de Madrid, Madrid, Espanha; \\ dfilippo@bib.uc3m.es \\ Elías Sanz Casado \\ Doutor; Universidad Carlos III de Madrid, Madrid, Espanha; \\ elias@bib.uc3m.es
}

\begin{abstract}
Resumo: Nos últimos anos, o sistema de educação superior brasileiro tem sido objeto de inúmeras políticas e uma delas é o Programa de Apoio a Planos de Reestruturação e Expansão das Universidades Federais (REUNI). O objetivo deste trabalho é analisar seu impacto na atividade investigativa das universidades federais, em três dimensões: crescimento, qualidade e internacionalização, estabelecendo uma relação entre os resultados do Programa REUNI e as publicações científicas na Web of Science. A partir de dados referentes ao período 2003-2012, observa-se que houve um incremento considerável na produção científica do Brasil e ainda mais nas universidades federais. A contratação de professores doutores tem aumentado, entretanto ainda não repercute na qualidade dos documentos em revistas de primeiro quartil. Os programas de mobilidade auxiliaram a promover a formação em diferentes países. Além disso, as publicações em colaboração internacional cresceram rapidamente, mas ainda não alcançaram percentuais destacados. Embora se evidencie uma importante transformação nas universidades federais, ainda faz-se necessário integrar esforços em direção à qualidade e à visibilidade internacional.
\end{abstract}

Palavras-chave: Análise bibliométrica. Sistema universitário brasileiro. Política Educacional. Universidades federais. REUNI. 


\section{Introdução}

A necessidade de se ajustar às novas demandas da economia mundial e a premência de integração ao sistema econômico global passaram a exigir dos países em desenvolvimento reformas na educação, considerada como uma estratégia essencial para melhorar a competitividade dos países (CASTRO; CABRAL NETO, 2012). Nas duas últimas décadas, a educação superior brasileira foi marcada por forte expansão sob todos os aspectos: cresceram os números de instituições, de cursos, de vagas, de ingressantes, de matrículas e de concluintes (RISTOFF, 2014). O processo de reforma desencadeado pelo Ministério de Educação (MEC) orientou-se pela necessidade de democratizar o acesso a esse nível de formação e de inserir as universidades no projeto de desenvolvimento nacional. Neste sentido, algumas ações foram implementadas, e dentre elas, o Programa de Apoio a Planos de Reestruturação e Expansão das Universidades Federais (REUNI), que foi criado com a finalidade de criar condições para a ampliação do acesso e permanência na educação superior em nível de graduação, aproveitando a estrutura física e os recursos humanos existentes nas universidades federais brasileiras (BRASIL, 2007).

Para as universidades que fizessem a adesão seriam oferecidos recursos para a ampliação de estruturas físicas e tecnológicas e contratação de docentes e técnicos, e como contrapartida as universidades deveriam apresentar um percentual de $90 \%$ de conclusões nos cursos de graduação e relação de 18 alunos por professor. De acordo com Lima, Azevedo e Catani (2008, p. 23), trata-se, em essência, de estabelecer uma política que procura estimular a adesão a um novo modelo de universidade e uma nova relação de trabalho com os professores.

Para Carvalho (2014), esta política pública é um conjunto sistêmico interdependente de sete pilares, a saber: autonomia, centralização do poder decisório, avaliação, formação de professores, flexibilização curricular, expansão e financiamento, que contribuíram para intervenção do poder público em prol da expansão da educação superior.

Como toda mudança, e a despeito das melhores intenções que possam ter seus proponentes, tal reforma da educação superior também vem encontrando 


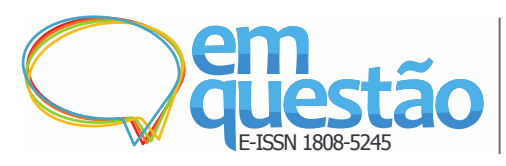

Impacto do Programa de Apoio a Planos de

Reestruturação e Expansão das Universidades Federais

(REUNI) na atividade investigativa: crescimento,

qualidade e internacionalização

Cláudia Daniele de Souza, Daniela De Filippo e Elías Sanz Casado

focos de resistência, sobretudo no âmbito das associações de servidores das Instituições Federais de Educação Superior (IFES) e do movimento estudantil.

Mais além das polêmicas geradas pela implementação do Programa, o objetivo deste estudo é descrever os propósitos e as diretrizes do REUNI, ademais de analisar o seu impacto na atividade investigativa das universidades federais na década 2003-2012. Para tanto, se consideram três principais dimensões: crescimento, qualidade e internacionalização. Foram utilizados indicadores quantitativos para verificar se o aumento do número de universidades, de professores e de doutores, além da cooperação internacional e mobilidade estudantil, se reflete na atividade investigativa medida através do número de publicações científicas indexadas na base de dados Web of Science (WoS) - de Thomson Reuters,--na quantidade de documentos em revistas de alto prestígio (designadas como primeiro quartil - Q1) e no número de publicações em colaboração internacional.

A estrutura do artigo está dividida em três seções, além dessa introdução, que contém a descrição do tema, da justificativa e dos objetivos propostos. Logo após discute-se a expansão da educação superior no Brasil, focada na implantação do Programa REUNI nas universidades federais brasileiras; é a abordagem conceitual e teórica que fundamenta a pesquisa. Em seguida, apresenta-se a metodologia utilizada no artigo. Há caracterização do método, das fontes de informação e dos softwares utilizados, bem como um detalhamento das dimensões e indicadores analisados na pesquisa. Posteriormente são expostos os resultados, com indicadores relacionados às três dimensões mencionadas, que contribuem para compor um panorama sobre o desenvolvimento da atividade científica após iniciada a expansão do ensino superior federal no Brasil. Em seguida estão as discussões e considerações finais do trabalho e, por último, as referências consultadas. 


\section{A expansão do ensino superior federal brasileiro}

O Programa de Apoio a Planos de Reestruturação e Expansão das Universidades Federais (REUNI), apresentado através do Decreto Presidencial n. 6.096/2007, está contido no plano de governo denominado Plano de Desenvolvimento da Educação (PDE), Programa que tem por base um conjunto de várias ações para a educação superior brasileira (BRASIL, 2007; LIMA, 2013). O PDE está associado ao Programa de Aceleração do Crescimento (PAC), que é uma série de medidas realizadas pelo Governo Luiz Inácio Lula da Silva com intuito de propiciar o crescimento econômico e social para o país. Uma importante medida do plano está em sua subdivisão territorial, pois desta maneira é possível identificar regiões até então desprivilegiadas de oportunidades educacionais, apresentando e atuando sobre as desigualdades encontradas (COSTA; COSTA; BARBOSA, 2013).

O REUNI tem como propósito dotar as universidades federais brasileiras das condições necessárias para que possa expandir as vagas no ensino superior e reduzir a evasão dos alunos, no nível de graduação, pelo melhor aproveitamento da estrutura física e dos recursos humanos existentes. Igualmente, ressalta a importância de propiciar a mobilidade estudantil e a ampliação de políticas de inclusão e de assistência estudantil (ARAÚJO; PINHEIRO, 2010).

As diretrizes estabelecidas para o Programa apontam para a pactuação de resultados, com metas quantitativas e qualitativas, em que predominam o enfoque de eficiência, flexibilidade, mobilidade e novos arranjos organizacionais na arquitetura do REUNI, evidenciando uma sintonia com propostas de inovações gerenciais de reforma do Estado:

a) redução das taxas de evasão, ocupação de vagas ociosas e aumento de vagas de ingresso, especialmente no período noturno;

b) ampliação da mobilidade estudantil, com a implantação de regimes curriculares e sistemas de títulos que possibilitem a construção de itinerários formativos, mediante o aproveitamento de créditos e a circulação de estudantes entre instituições, cursos e programas de educação superior;

c) revisão da estrutura acadêmica, com reorganização dos cursos de graduação e atualização de metodologias de ensino - aprendizagem, buscando a constante elevação da qualidade; 
d) diversificação das modalidades de graduação, preferencialmente não voltadas à profissionalização precoce e especializada;

e) ampliação de políticas de inclusão e assistência estudantil; e

f) articulação da graduação com a pós-graduação e da educação superior com a educação básica.

Para a realização dessas diretrizes, o REUNI estruturou-se em seis dimensões (Figura 1) combinadas no plano de reestruturação.

Figura 1 - Diretrizes para o Programa REUNI estruturadas em seis dimensões.

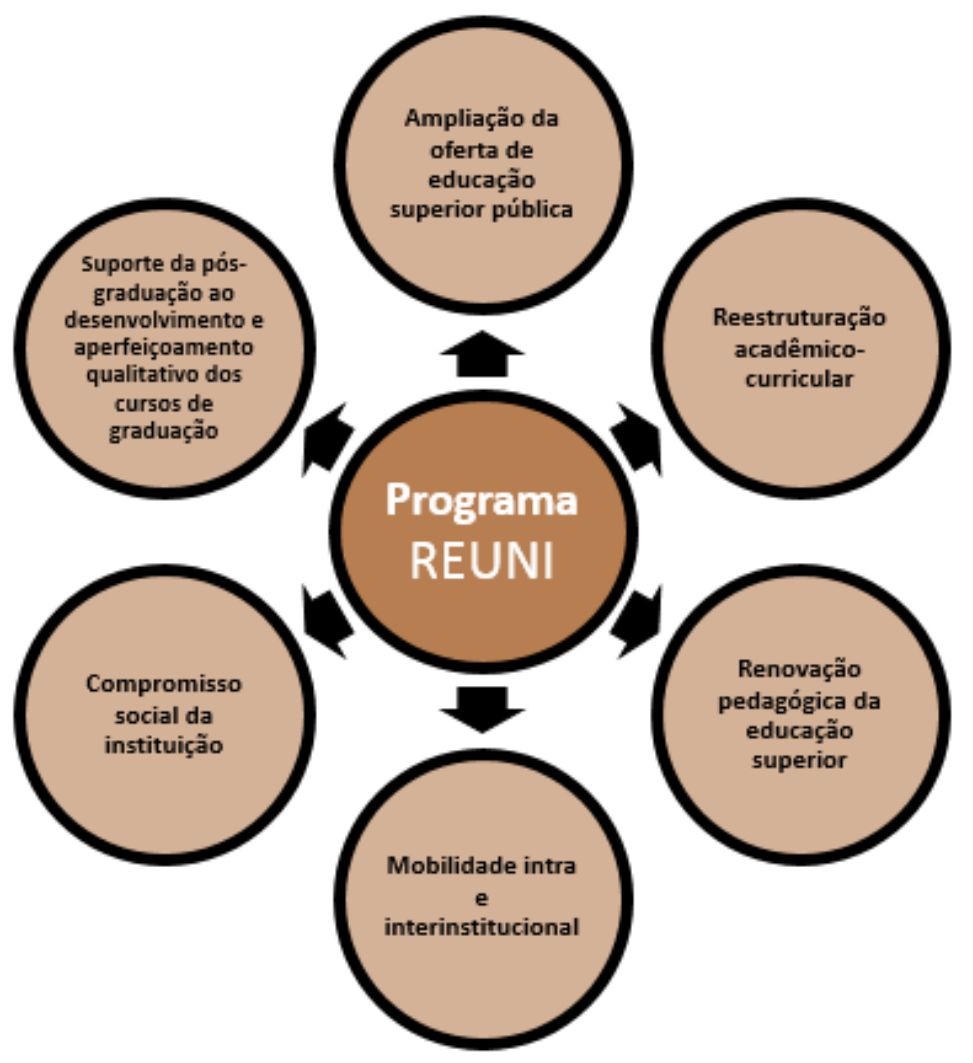

Fonte: Programa REUNI (REESTRUTURAÇÃO..., 2015)

Em cada uma dessas dimensões, as universidades deveriam propor ações para obter as condições de reestruturar-se, garantindo ampliação de suas instalações físicas e ampliando sua presença nas regiões do país que antes não contavam com estruturas universitárias (REESTRUTURAÇÃO..., 2015). Em 2008, o Programa distribuiu o montante de R\$ 491.882.340,00 (cerca de US\$ 280 mi- 
lhões) para as 53 universidades federais brasileiras ${ }^{1}$ que aderiram ao Programa (SILVA; ADEODATO, 2012).

Para Carvalho (2014, p. 216), o Programa explicita duplo intuito: manter o crescimento absoluto do sistema educacional de nível superior e, simultaneamente, redirecionar parcialmente os instrumentos existentes em prol do segmento federal. O REUNI foi de adesão voluntária de cada instituição, por decisão dos respectivos Conselhos Universitários. A Figura 2, retirada da página do próprio Programa (REESTRUTURAÇÃO..., 2015), ilustra a localização geográfica, mostrando que houve adesão da totalidade das universidades federais brasileiras existentes no ano de sua criação. Segundo o relatório do primeiro ano do REUNI, tais universidades pactuaram um montante de 3.459 cargos, sendo 1.821 de docentes e 1.638 técnicos (MINISTÉRIO..., 2009).

Figura 2 - Localização geográfica das 53 universidades federais brasileiras que aderiram ao Programa REUNI

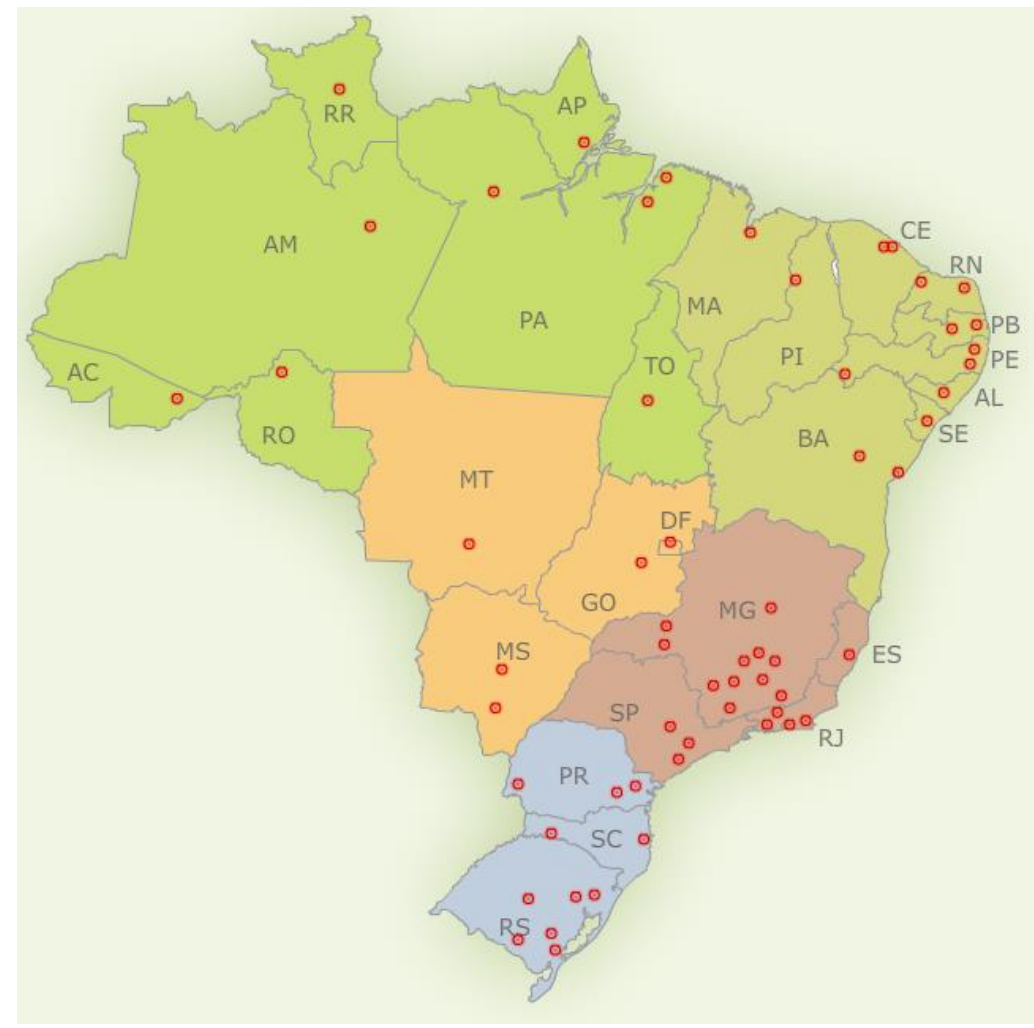

Fonte: Programa REUNI (REESTRUTURAÇÃO..., 2015) 


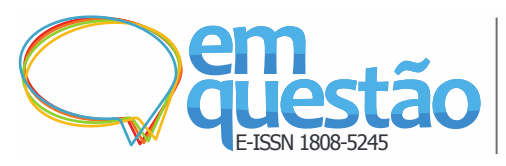

Impacto do Programa de Apoio a Planos de

Reestruturação e Expansão das Universidades Federais

(REUNI) na atividade investigativa: crescimento,

qualidade e internacionalização

Cláudia Daniele de Souza, Daniela De Filippo e Elías Sanz Casado

Entretanto, tal aceitação foi inevitável e não ocorreu imune a polêmicas e discussões (SILVA; FREITAS; LINS, 2013). Estudantes, docentes e técnicoadministrativos em todo o país manifestaram-se contrários. Reitorias foram ocupadas, atos públicos foram realizados e outras formas de mobilização foram deflagradas a fim de impedir a adesão ao Programa; contudo, se uma universidade não aderisse ao Programa, não receberia as verbas públicas para o desenvolvimento de suas atividades pedagógicas (SILVA, 2014).

Cada instituição deveria prever no seu plano as ações que pretenderia levar a cabo para o cumprimento das metas; em contrapartida, receberia recursos adicionais condicionados ao cumprimento das metas estabelecidas para cada etapa, limitados a $20 \%$ do orçamento de custeio e pessoal do ano inicial de adesão e no prazo de cinco anos; financiamento esse condicionado à capacidade orçamentária e operacional do Ministério da Educação (MEC) (TONEGUTTI; MARTINEZ, 2008; LIMA, 2010).

Para Lima, Azevedo e Catani (2008, p. 23), esse conjunto de condições foi uma forma de estimular a concorrência entre as universidades federais; tratase de uma competição de regularidade e de busca de identidade ao modelo sugerido pelo MEC. Na opinião de Santos (2009, p. 31), a circunstância de que as políticas governamentais direcionadas à educação superior são trabalhadas em caráter de urgência nos círculos acadêmicos já é de longa data. Dessa forma, o REUNI ficou limitado à previsão orçamentária concedida, não havendo a garantia da efetividade, da continuidade e do cumprimento de desembolsos acordados inicialmente (BORGES; AQUINO, 2012).

Como um dos primeiros resultados dessa iniciativa, houve um crescimento de 20,4\% de matrículas nos cursos de graduação presencial, porém, Lima (2013, p. 101) adverte que foi ao custo de salas superlotadas e alocação de recursos insuficientes para a continuidade da expansão.

Ainda se faz necessária uma análise mais acurada que cruze os dados de expansão e orçamento, o que ainda não foi disponibilizado. Todavia, com as investigações qualitativas já realizadas em algumas universidades federais Universidade Federal do Maranhão (UFMA) (SOUSA; COIMBRA; SOUSA, 
2011); Universidade Federal do Pará (UFPA) (PRESTES; JEZINE; SCOCUGLIA, 2012); Universidade Federal Fluminense (UFF) (GREGÓRIO, 2012); Universidade Federal de Juiz de Fora (UFJF) (WESKA, 2012); Universidade Federal de Uberlândia (UFU) (ZAGO, 2013); Universidade Federal de Santa Catarina (UFSC) (SILVA, 2014) e Universidade Federal de São João del-Rei (UFSJ) (ARAÚJO; SANTOS, 2014), enunciam-se as hipóteses de que a expansão da educação superior brasileira acarretou mais trabalho ao professor, visto que a explosão do número de vagas discentes nas universidades federais tem ocorrido sem a correspondente ampliação das vagas docentes; além do aligeiramento do ensino, particularmente pela flexibilização de currículos e o uso da Educação a Distância (EaD), intensificando o processo de certificação em larga escala (MANCEBO, 2015).

Em síntese, devido à diversidade da estrutura e sua organização,descrever como tem ocorrido a expansão da educação superior no Brasil com o Programa REUNI é uma tarefa árdua e complexa. Faz-se necessário entender o contexto atual, levando-se em conta outros fatores como os econômicos, sociais e culturais (STALLIVIERI, 2007). Para aprofundamento no tema, recomenda-se a obtenção de mais informações nos trabalhos de Michelotto, Coelho e Zainko (2006), Araújo e Pinheiro (2010), Borsoi (2012), Sguissardi e Silva Junior (2012), Lima (2013) e Zambello (2013).

\section{Metodologia}

Dada a importância das políticas de educação superior que foram desenvolvidas no Brasil nos últimos anos, neste trabalho estuda-se o seu impacto no âmbito da atividade investigativa de um dos programas mais extensos. Mais além dos efeitos positivos ou negativos do Programa REUNI, o objetivo é apresentar uma série de ferramentas que permitam quantificar e medir de maneira "objetiva" os efeitos das políticas sobre a atividade investigadora.

Em função dos objetivos, o trabalho foi concebido como uma pesquisa exploratória- por procurar padrões, ideias que evidenciem o problema e/ou ten- 
tam conhecê-lo melhor; e descritiva- na medida em que é usada para identificar e obter informações sobre as características de um determinado problema ou questão, conhecer os fatores envolvidos e buscar descrever o comportamento dos fenômenos com exploração bibliográfica (COLLINS; HUSSEY, 2005).

Para analisar o impacto do REUNI sobre a atividade investigativa, foram associados três aspectos importantes do Programa com três âmbitos de pesquisa das universidades federais brasileiras:
a) crescimento;
b) impacto;
c) internacionalização.

Foram utilizados como fontes de informação documentos oficiais, relatórios do Programa REUNI e também a base de dados internacional Web of Science para a obtenção de indicadores bibliométricos. Por amenizar os elementos de julgamento e produzir indicadores quantitativos,atribuindo mais objetividade aos resultados(LASCURAIN SÁNCHEZ, 2006), a bibliometria mostrou ser uma ferramenta eficiente na análise e avaliação da produção científica e do seu impacto nas universidades federais brasileiras.

Desse modo, contando com o auxílio de ferramentas bibliométricas, para cada uma das três dimensões foi selecionada uma série de indicadores com o intuito de comparar o alcance do Programa com os resultados bibliométricos. A Tabela 1 detalha as dimensões e os indicadores analisados.

Tabela 1- Dimensões e indicadores utilizados para analisar o impacto do Programa REUNI nasuniversidades federais brasileiras

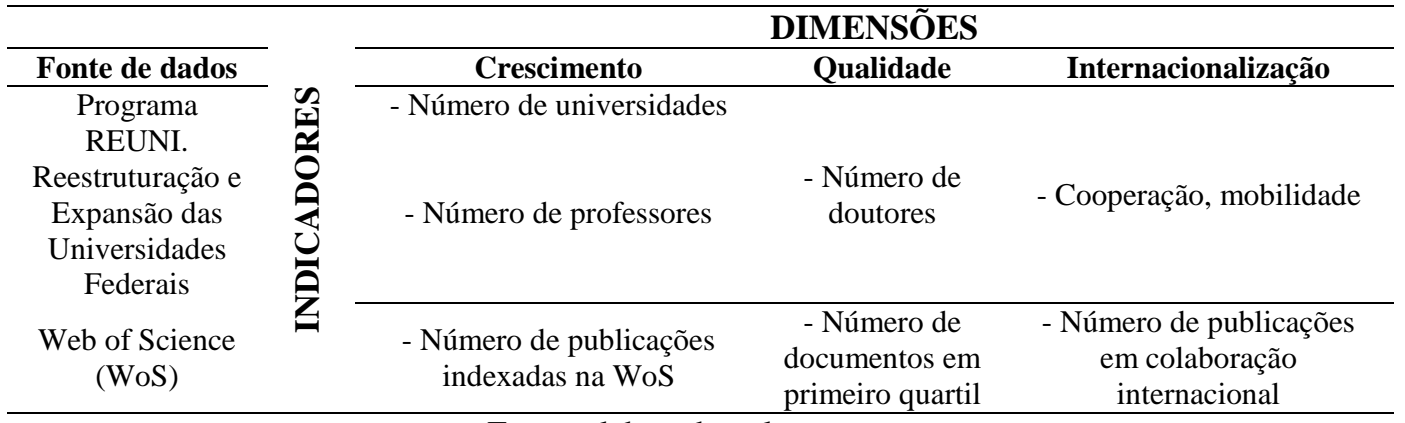

Fonte: elaborado pelos autores 
O primeiro passo dado na metodologia foi realizar o download da produção científica brasileira indexada na $\mathrm{WoS}^{2}$. Para tanto, utilizou-se a opção de busca avançada com a seguinte estratégia: ((CU=Brazil) AND (PY=20032012) $)^{3}$. Em seguida, sabendo-se que entre os resultados mais interessantes de qualquer trabalho bibliométrico encontra-se o estudo das instituições que assinam as publicações, realizou-se a identificação e normalização de todas as instituições firmantes. Devido às diferentes maneiras que os autores registram seus endereços, esse é um trabalho complexo e complicado que normalmente consome uma grande quantidade de tempo dedicado à normalização nos nomes institucionais (MUGNAINI, JANNUZZI, QUONIAM, 2004; VANZ, 2009). Neste caso, utilizou-se uma ferramenta desenvolvida no Laboratório de Estudos Métricos de Informação (LEMI) que, através do uso de expressões regulares, permite identificar as diferentes variantes de firma de uma mesma instituição, possibilitando identificar a produção das universidades federais.

Para a dimensão crescimento, detalhou-se a cronologia de criação das universidades federais, além de se examinar a evolução do número de professores efetivos, substitutos e visitantes entre os anos 2003-2012. Analisou-se também como se deu o aumento da produção científica na Web of Science considerando os seguintes indicadores:

a) número anual de documentos do Brasil;

b) número anual de documentos do sistema universitário;

c) número anual de documentos das universidades federais brasileiras;

d) crescimento interanual do número de publicações.

Para a segunda dimensão, qualidade, averiguou-se a titulação dos docentes (Graduação, Especialização, Mestrado e Doutorado) das universidades federais brasileiras ao longo do período. Na parte dos indicadores bibliométricos, foram analisados os documentos publicados em revistas de primeiro quartil (Q1)-que a estatística descritiva apresenta como qualquer um dos valores que divide o conjunto ordenado de dados em quatro partes iguais, e cada parte representa 1/4 da amostra ou população. Neste caso, os documentos que estão incluídos nos $25 \%$ das revistas melhor posicionadas por seus fatores de impacto (GARFIELD, 1994). Os indicadores obtidos foram: 
a) número de documentos em Q1 por ano na produção brasileira, do Sistema Universitário e das universidades federais;

b) porcentagem de documentos em Q1 sobre o total da produção brasileira, do Sistema Universitário e das universidades federais;

c) crescimento interanual do número e porcentagem de documentos em Q1.

Para a última dimensão, internacionalização, explorou-se a distribuição das bolsas implementadas pelo Programa Ciência Sem Fronteiras, por modalidade e país de destino. No âmbito bibliométrico, os indicadores obtidos foram:

a) número de documentos em colaboração internacional (firmados por Brasil e pelo menos outro país) do Brasil, do Sistema Universitário e das universidades federais;

b) porcentagem de documentos em colaboração internacional sobre o total da produção do Brasil, do Sistema Universitário e das universidades federais;

c) aumento anual da colaboração científica internacional;

d) estudou-se o impacto através do número e porcentagem de documentos publicados pelas universidades federais em colaboração internacional.

\section{Resultados}

Nesta seção estão expostos os resultados da pesquisa. Apresentam-se indicadores bibliométricos relacionados a três dimensões: crescimento, qualidade e internacionalização, que auxiliam na análise do impacto do programa REUNI na atividade investigativa das universidades federais na década 2003-2012. 


\subsection{Dimensão1: Crescimento}

Dado que cada vez é mais notório o interesse por estudos que permitam visualizar o quanto a ciência tem aumentado ao longo do tempo, apresenta-se a seguir os resultados da pesquisa relacionados ao crescimento do programa REUNI e também seu reflexo na produção científica brasileira.

\subsubsection{Programa REUNI}

A Educação Superior no Brasil, nas últimas quatro décadas, passou por duas fases de expansão. Dos anos 1964 a 1980 aumentou dez vezes o número de matrículas nesse nível de ensino. A segunda fase de expansão iniciou-se a partir de 1995 (BORGES; AQUINO, 2012). Por conseguinte, na última década, houve um grande crescimento do Ensino Superior Brasileiro (Figura 3), com a criação de 18 novas universidades federais.

Figura 3 - Cronologia de criação das universidades federais brasileiras

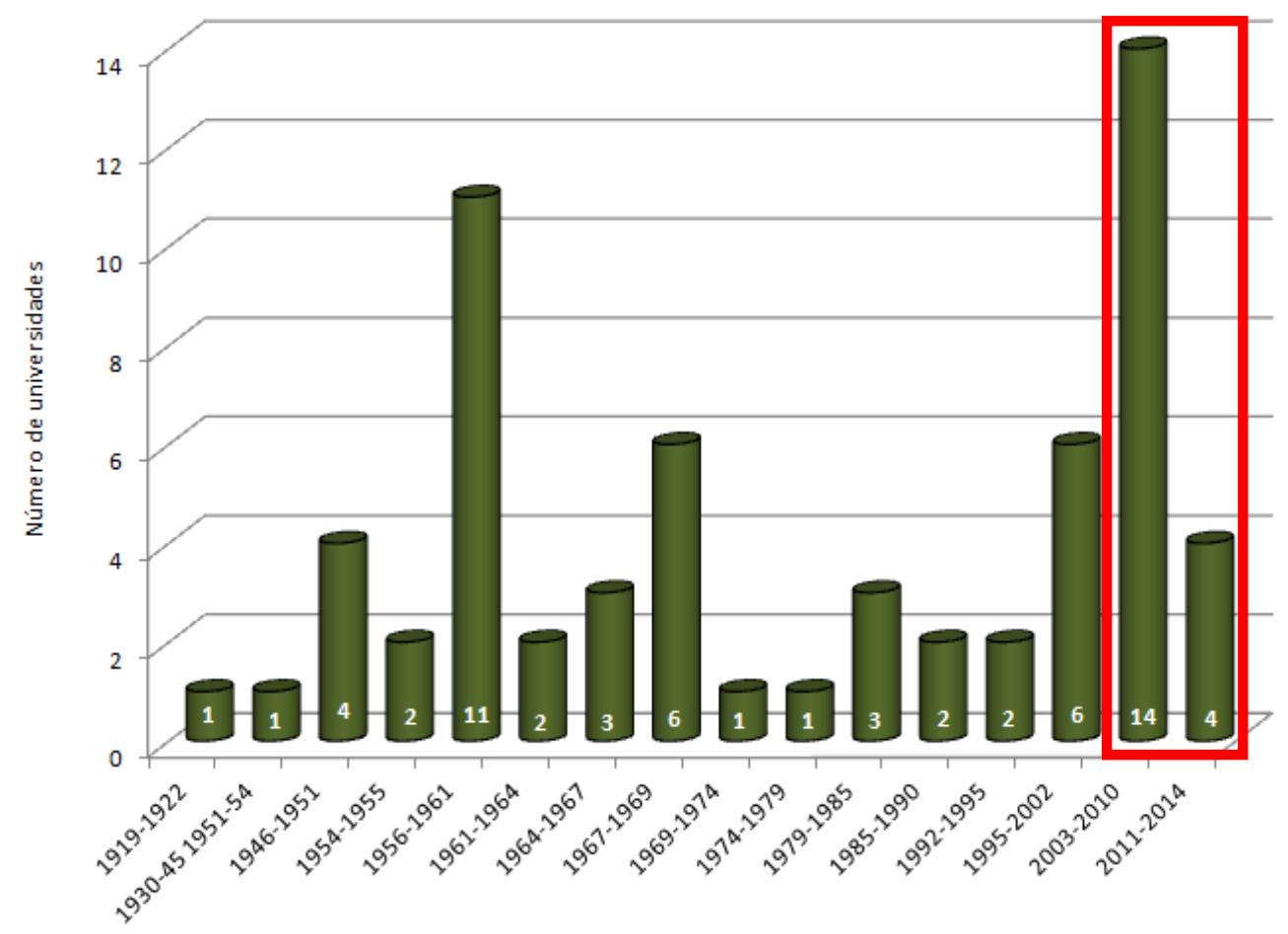

Fonte: Brasil (2015) 
A partir da Figura 4, observa-se um crescimento global do número de docentes - especialmente entre os permanentes - nas universidades federais brasileiras. No período 2003-2012, aumentou-se aproximadamente 44\%.

Figura 4- Crescimento do número de professores nas universidades federais brasileiras

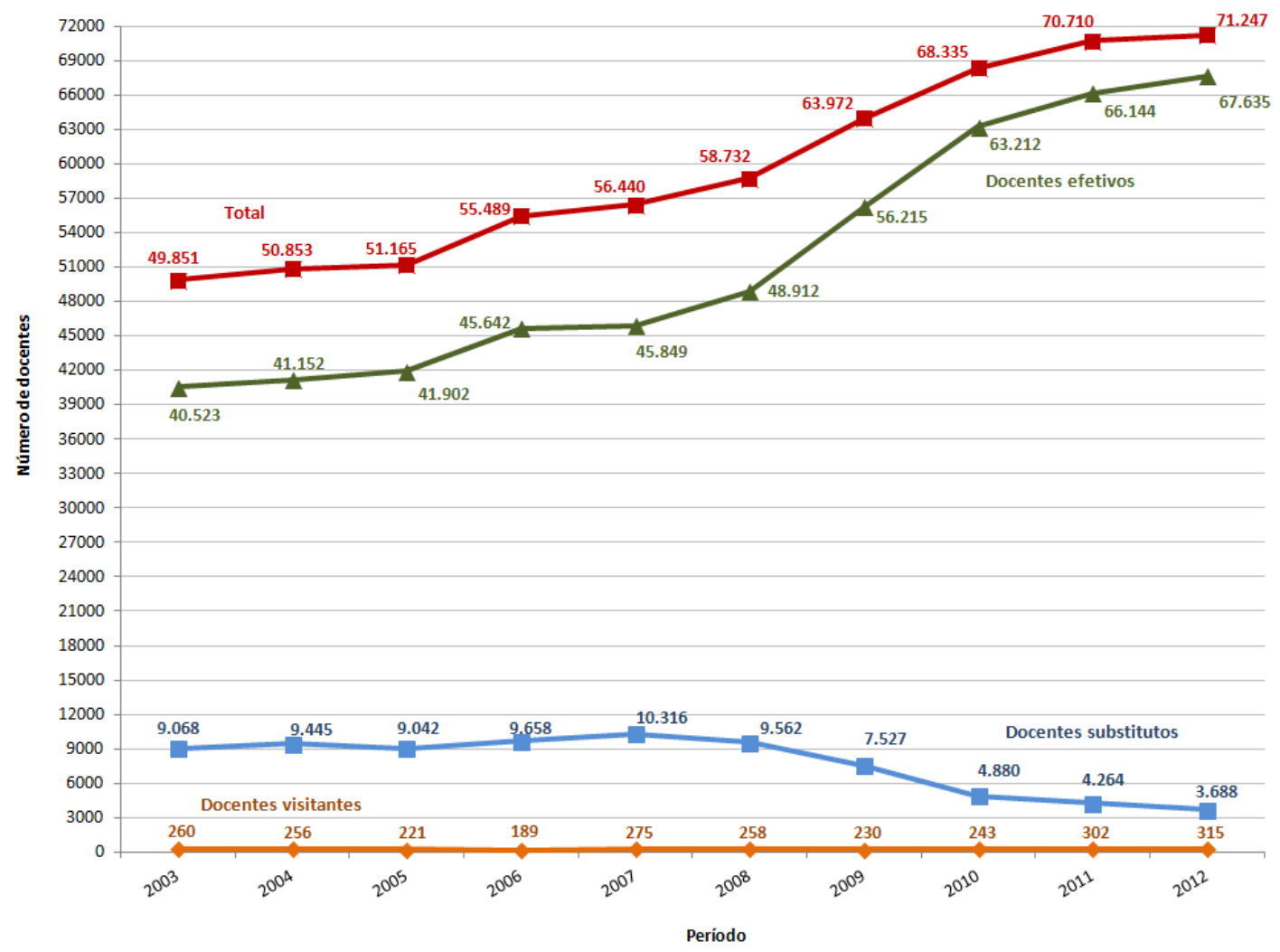

Fonte:Elaboração própria a partir deBrasil (2015)

Evidencia-se que no período de implementação do REUNI- entre 2008 e 2012 - houve um grande salto no número de docentes efetivos (com a autorização de 21.786 novas vagas docentes) e a consequente redução de $64 \%$ de docentes substitutos. Houve também uma ampliação aproximada de $22 \%$ no número de professores visitantes. 


\subsubsection{Publicações na Web of Science}

Integrando esforços com os Programas desenvolvidos pela Coordenação de Aperfeiçoamento de Pessoal de Nível Superior (CAPES), consequentemente, a produção científica das universidades federais brasileiras também aumentou (Figura 5).

Figura 5 - Crescimento da produção científica do Brasil, do sistema universitário e das universidades federais brasileiras.

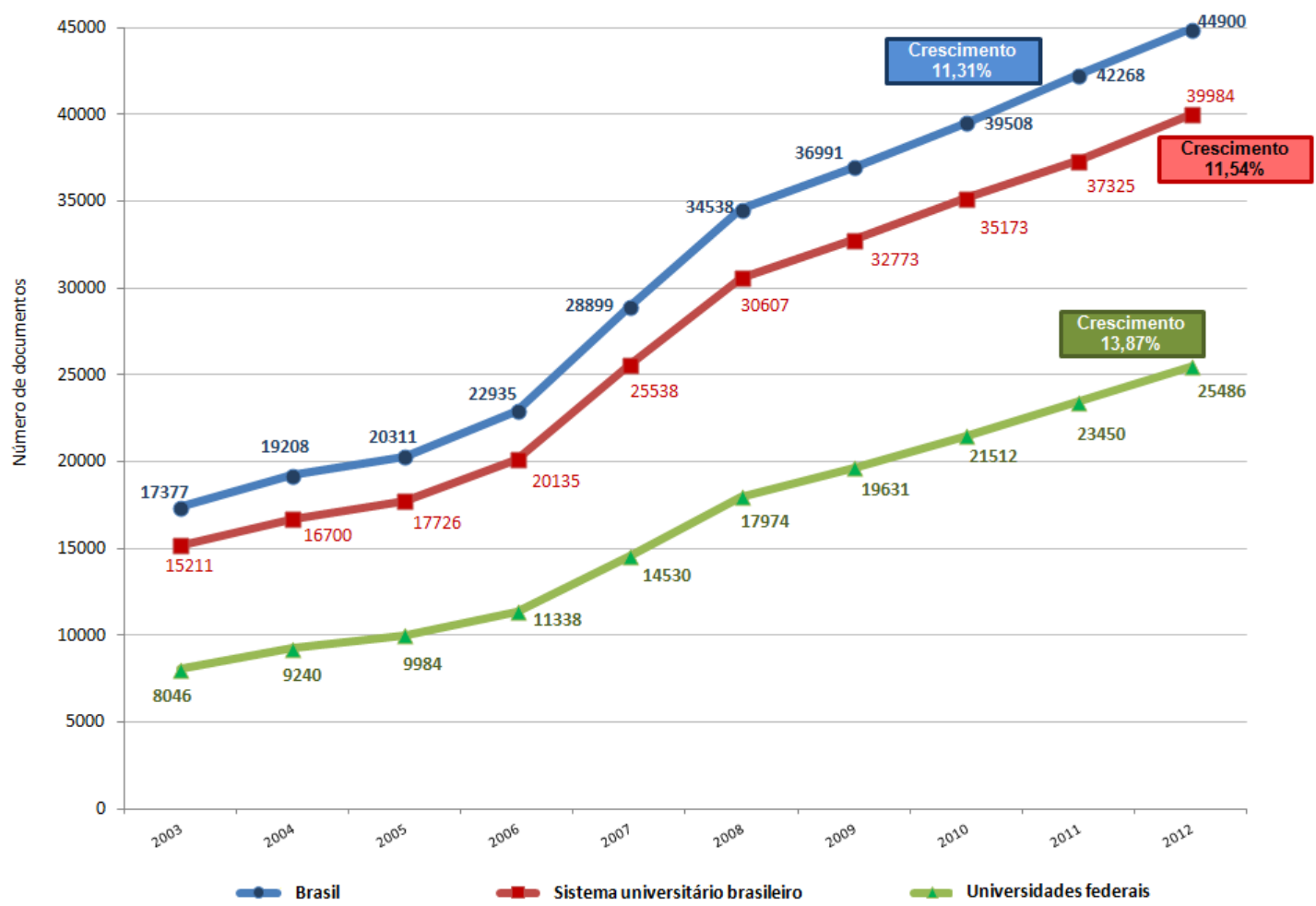

Fonte: elaboração própria a partir de dados obtidos na Web of Science

Entre os anos 2003 e 2012, o número de publicações brasileiras indexadas na Web of Science passou de 17.377 para 44.900, evidenciando uma média de crescimento interanual de $11,31 \%$. Desse total, $88 \%$ estava concentrado no Sistema de Educação Superior, que apresentou média de crescimento interanual de $11,54 \%$. As universidades federais foram as instituições que mais aumentaram a produção $(13,87 \%)$ e foram ganhando espaço no setor educativo, uma vez 


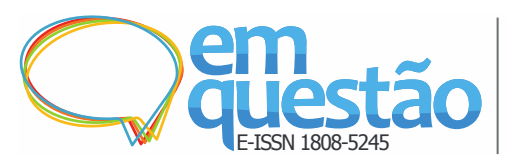

Impacto do Programa de Apoio a Planos de

Reestruturação e Expansão das Universidades Federais

(REUNI) na atividade investigativa: crescimento,

qualidade e internacionalização

Cláudia Daniele de Souza, Daniela De Filippo e Elías Sanz Casado

que em 2003 representavam aproximadamente a metade(53\%) do sistema universitário e no final do período analisado chegaram a $64 \%$.

Ao desagregar a produção científica em nível institucional, a Figura 6 apresenta as vinte universidades federais mais produtivas, a quantidade de documentos publicados, bem como suas respectivas médias de crescimento interanual no período 2003-2012.

Figura 6 - Número de documentos publicados e média de crescimento anual das universidades federais brasileiras mais produtivas (2003-2012)

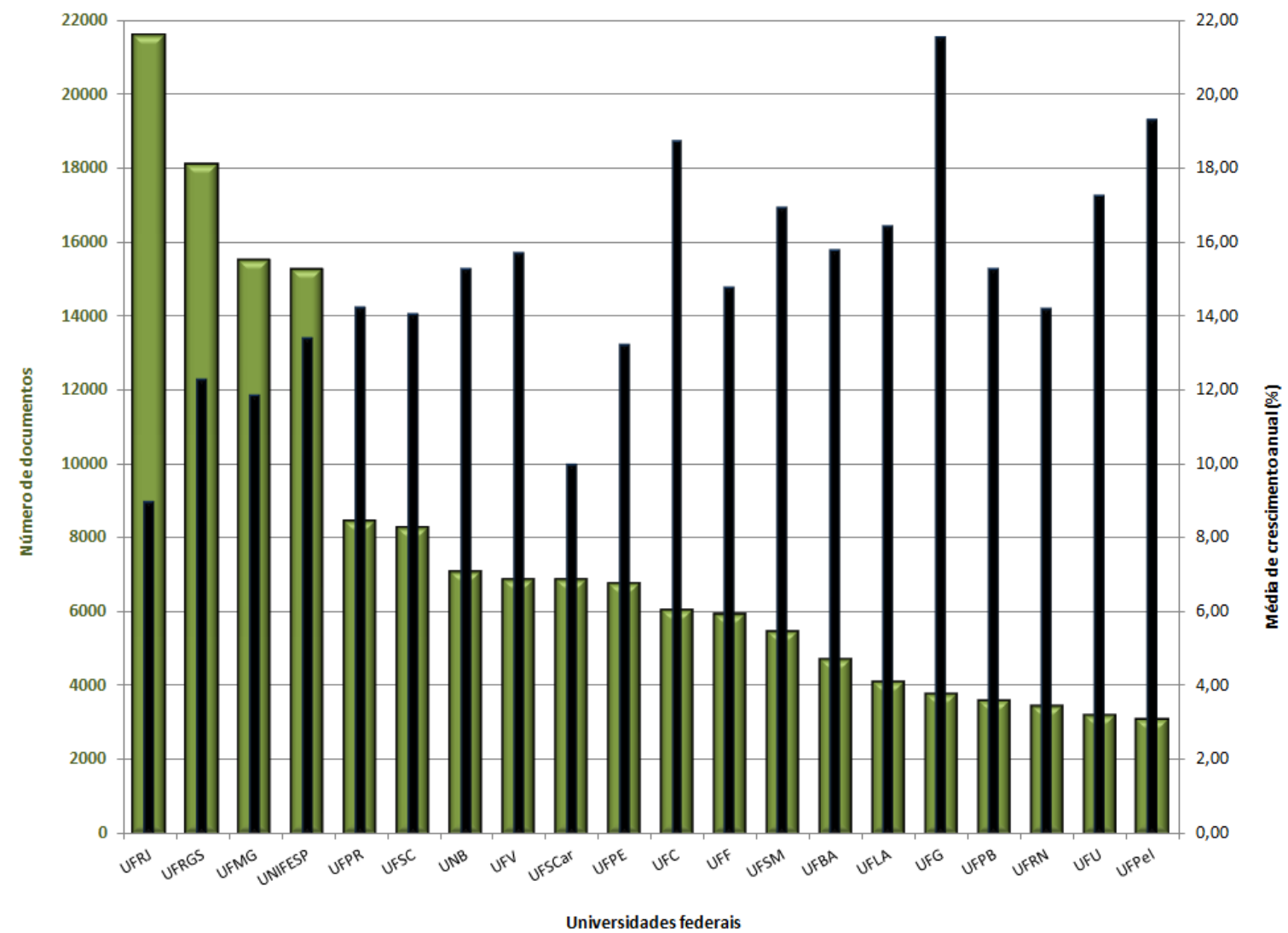

Fonte: elaboração própria a partir de dados obtidos na Web of Science

Algumas destas instituições não foram tão produtivas, mas tiveram importante crescimento no volume total de suas publicações, como é o caso da Universidade Federal de Goiás (UFG), que quintuplicou o número de documentos, passando de 130 em 2003 para 694 em 2012. 


\subsection{Dimensão 2: Qualidade}

Atualmente a avaliação da produção científica brasileira tem sido muito discutida, especialmente nas universidades públicas. Apresenta-se a seguir os resultados da pesquisa relacionados à qualidade docente e também o seu reflexo na produção científica indexada na base de dados WoS.

\subsubsection{Programa REUNI}

O número de professores doutores aumentou de 50,95\% para $68,78 \%$ entre os anos 2003-2012. A tabela 2 apresenta o panorama sobre a titulação docente nas universidades federais brasileiras no período de 2003-2012. No primeiro ano analisado, observa-se que contavam com $6,55 \%$ de docentes apenas com graduação, 10,33\% especialistas, 32,47\% mestres e 50,95\% doutores. Em 2012 esses números passaram por uma grande modificação, com a redução do número de docentes somente graduados para apenas $2,01 \%$ e docentes especialistas para $3,75 \%$. Entretanto, a maior diferença aconteceu entre os docentes mestres e doutores, com a redução para $25,45 \%$ do quantitativo de mestres e um crescimento relevante no número de doutores, alcançando o percentual de $68,78 \%$.

Tabela 2 - Titulação dos docentes das universidades federais brasileiras (2003-2012)

\begin{tabular}{ccccc}
\hline Anos & Graduação & Especialização & Mestrado & Doutorado \\
\hline 2003 & $6,55 \%$ & $10,03 \%$ & $32,47 \%$ & $50,95 \%$ \\
2004 & $5,87 \%$ & $9,08 \%$ & $30,88 \%$ & $54,17 \%$ \\
2005 & $5,25 \%$ & $8,36 \%$ & $29,08 \%$ & $57,30 \%$ \\
2006 & $4,52 \%$ & $7,47 \%$ & $28,18 \%$ & $59,83 \%$ \\
2007 & $4,02 \%$ & $6,93 \%$ & $26,54 \%$ & $62,50 \%$ \\
2008 & $3,55 \%$ & $6,23 \%$ & $25,71 \%$ & $65,52 \%$ \\
2009 & $3,09 \%$ & $5,33 \%$ & $26,27 \%$ & $63,50 \%$ \\
2010 & $2,54 \%$ & $4,60 \%$ & $27,12 \%$ & $65,74 \%$ \\
2011 & $2,21 \%$ & $4,07 \%$ & $26,36 \%$ & $67,36 \%$ \\
2012 & $2,01 \%$ & $3,75 \%$ & $25,45 \%$ & $68,78 \%$ \\
\hline
\end{tabular}

Fonte: elaboração própria a partir de Brasil (2015) 


\subsubsection{Publicações na Web of Science}

Como contrapartida da qualidade docente, analisou-se a qualidade da produção científica através do número e da percentagem de documentos publicados em revistas Q1. A Tabela3 mostra o número de artigos em Q1 tanto no Brasil, como no sistema universitário em geral e nas universidades federais em particular. Observa-se que em termos absolutos o crescimento foi notável, em todos os três casos, especialmente nas publicações das universidades, passando-se de 2.987 documentos publicados em 2003 para 7.851 no final do período analisado.

Tabela 3 - Número de documentos publicados em primeiro quartil

\begin{tabular}{c|cc|cc|cc}
\hline Anos & Todo o Brasil & $\begin{array}{c}\text { \% crescimento } \\
\text { interanual }\end{array}$ & $\begin{array}{c}\text { Sistema universitário } \\
\text { brasileiro }\end{array}$ & $\begin{array}{c}\text { \% crescimento } \\
\text { interanual }\end{array}$ & $\begin{array}{c}\text { Universidades } \\
\text { federais }\end{array}$ & $\begin{array}{c}\text { \% crescimento- } \\
\text { interanual }\end{array}$ \\
\hline 2003 & 8.705 & & 6.395 & & 2.987 & \\
2004 & 8.872 & $1,92 \%$ & 5.976 & $-6,55 \%$ & 3.132 & $4,85 \%$ \\
2005 & 9.145 & $3,08 \%$ & 6.133 & $2,63 \%$ & 3.227 & $3,03 \%$ \\
2006 & 10.043 & $9,82 \%$ & 6.813 & $11,09 \%$ & 3.547 & $9,92 \%$ \\
2007 & 11.542 & $14,93 \%$ & 7.820 & $14,78 \%$ & 4.284 & $20,78 \%$ \\
2008 & 12.945 & $12,16 \%$ & 8.653 & $10,65 \%$ & 4.902 & $14,43 \%$ \\
2009 & 13.610 & $5,14 \%$ & 9.145 & $5,69 \%$ & 5.264 & $7,38 \%$ \\
2010 & 15.924 & $17,00 \%$ & 10.733 & $17,36 \%$ & 6.179 & $17,38 \%$ \\
2011 & 15.836 & $-0,55 \%$ & 10.813 & $0,75 \%$ & 6.679 & $8,09 \%$ \\
2012 & 18.260 & $15,31 \%$ & 12.664 & $17,12 \%$ & 7.851 & $17,55 \%$ \\
Total & 124.882 & $8,75 \%$ & 85.145 & $8,17 \%$ & 48.052 & $11,49 \%$ \\
\hline
\end{tabular}

Fonte: elaboração própria a partir de dados obtidos na Web of Science.

No entanto, em termos relativos (Figura 7), a porcentagem de documentos publicados em revistas de Q1 decaiu consideravelmente. Em 2003, exatamente a metade das publicações brasileiras estava indexada em revistas de Q1, enquanto que na produção do sistema universitário, a porcentagem era 42,04\% e a das universidades federais $37,12 \%$. Todos esses valores caíram aproximadamente 10 pontos percentuais, fazendo com que o país chegasse ao final do período analisado com 40,67\% de documentos publicados em revistas de Q1, o sistema universitário com $31,67 \%$ e as universidades federais com $30,81 \%$. 


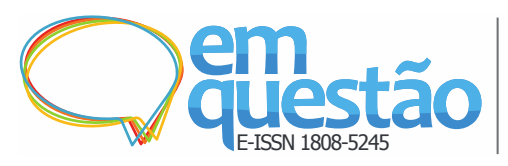

Impacto do Programa de Apoio a Planos de

Reestruturação e Expansão das Universidades Federais

(REUNI) na atividade investigativa: crescimento, qualidade e internacionalização

Cláudia Daniele de Souza, Daniela De Filippo e Elías Sanz Casado

Figura 7- Porcentagem de documentos publicados em primeiro quartil sobre o total da produção na WoS.

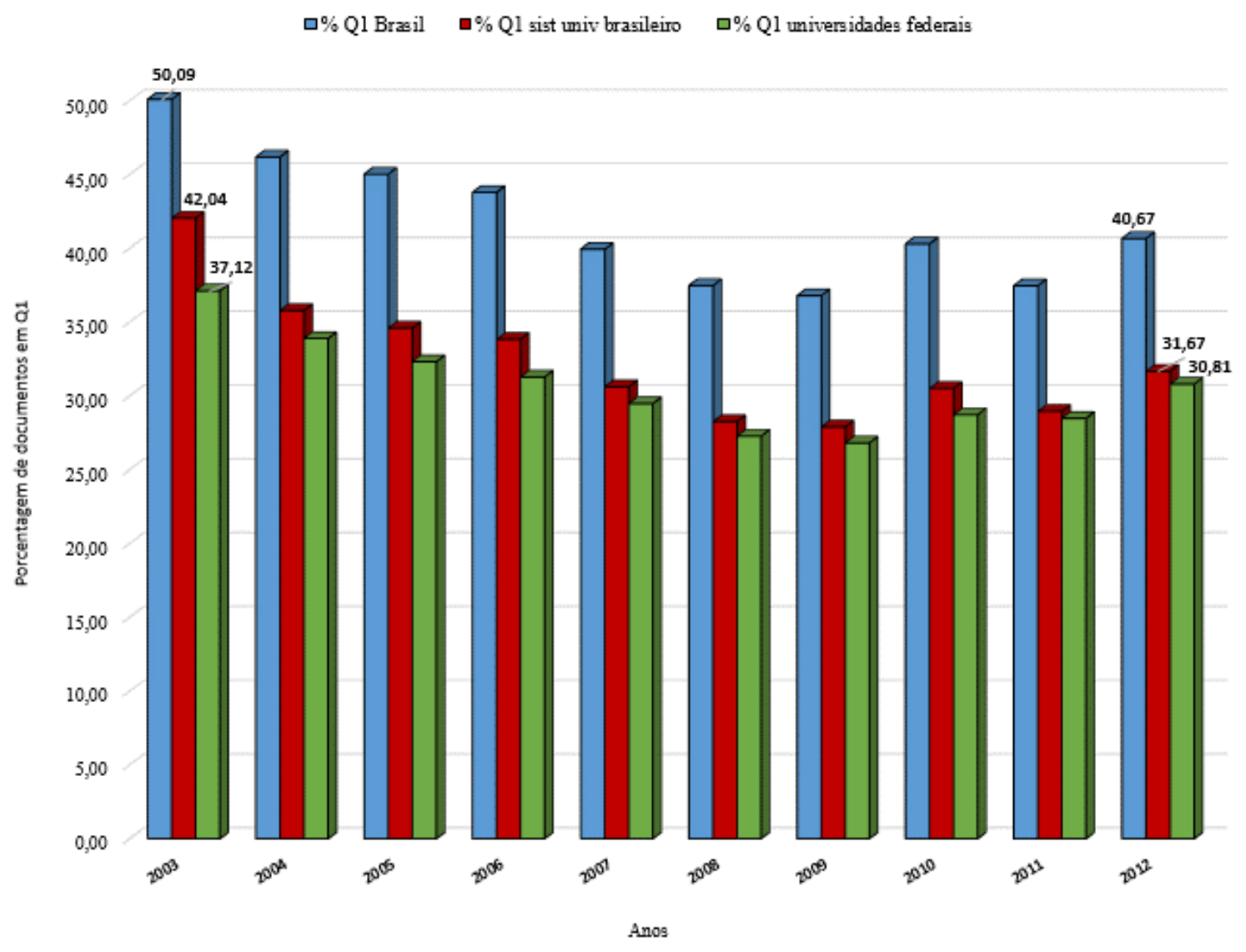

Fonte: elaboração própria a partir de dados obtidos na Web of Science

\subsection{Dimensão 3: Internacionalização}

A cooperação internacional por meio do ensino, da pesquisa e da extensão vem sendo cada vez estimulada no Brasil. Apresenta-se a seguir os resultados da pesquisa relacionados à internacionalização das universidades federais brasileiras e também seu reflexo na produção científica.

\subsubsection{Programa REUNI}

Nos últimos anos, a mobilidade nas universidades federais brasileiras cresceu muito com oPrograma Ciência Sem Fronteiras, que busca promover a consoli- 
dação, expansão e internacionalização da ciência e tecnologia, da inovação e da competitividade brasileira por meio do intercâmbio internacional. Desde o início do Programa até o mês de março/2015, 78.173 bolsas foram implementadas, sendo especialmente relevantes as de graduação sanduíche no exterior (figura 8).

Figura 8 - Distribuição das bolsas implementadas pelo Programa Ciência Sem Fronteiras, por modalidade

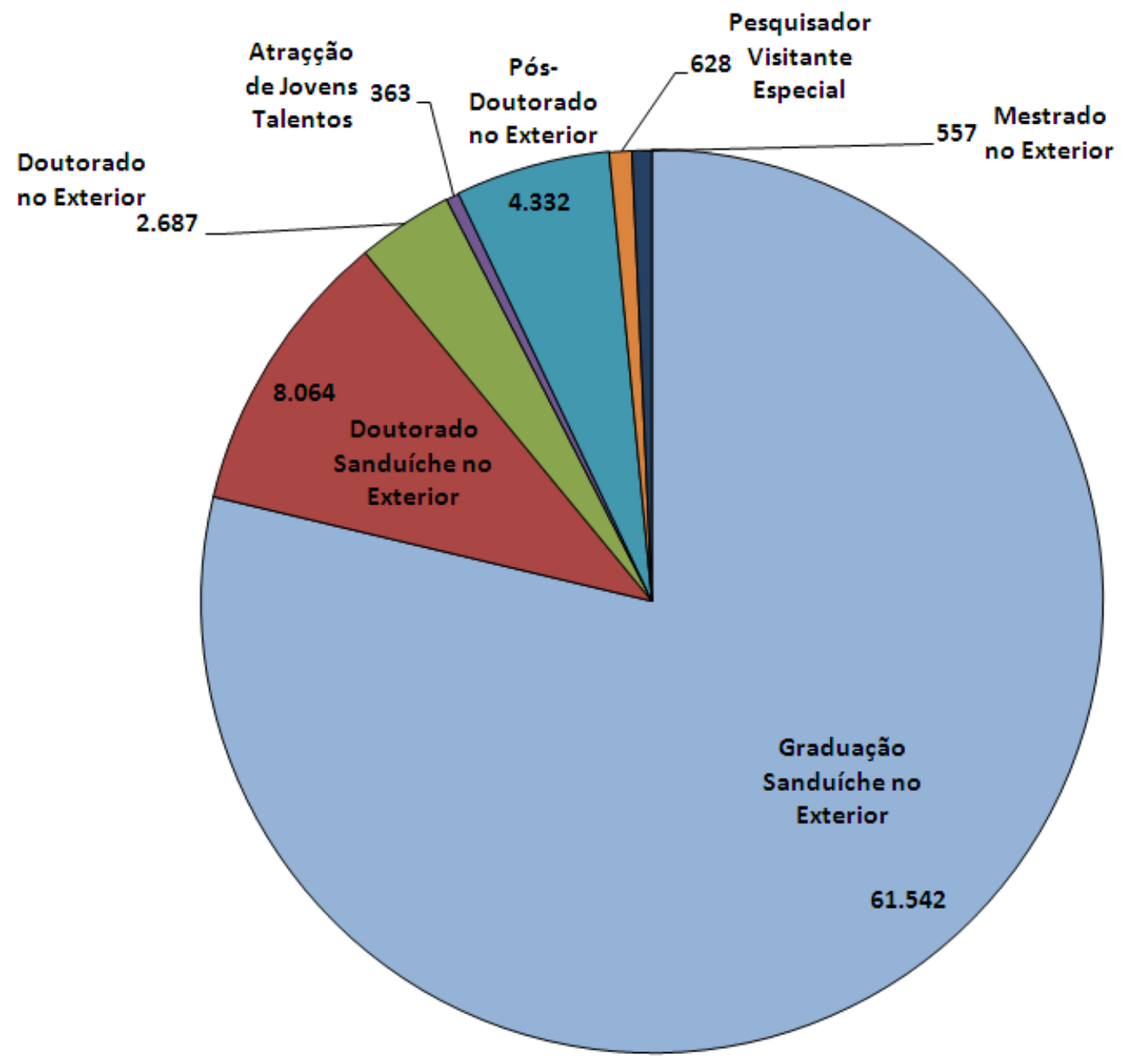

Fonte: elaboração própria a partir de dados obtidos no Programa Ciência Sem Fronteiras(2015)

Através da Figura 9, observa-se que entre os anos de 2003-2012 os programas de mobilidade internacional das universidades federais brasileiras tive- 
ram como destino principalmente os países do Grupo dos Sete (G7), ou seja, os sete países mais industrializados do mundo e com ampla base de pesquisa. Destaque para os Estados Unidos, país responsável por $28 \%$ das bolsas já implementadas.

Figura 9- Distribuição de bolsas efetivadas pelo Ciência Sem Fronteiras, por país de destino.

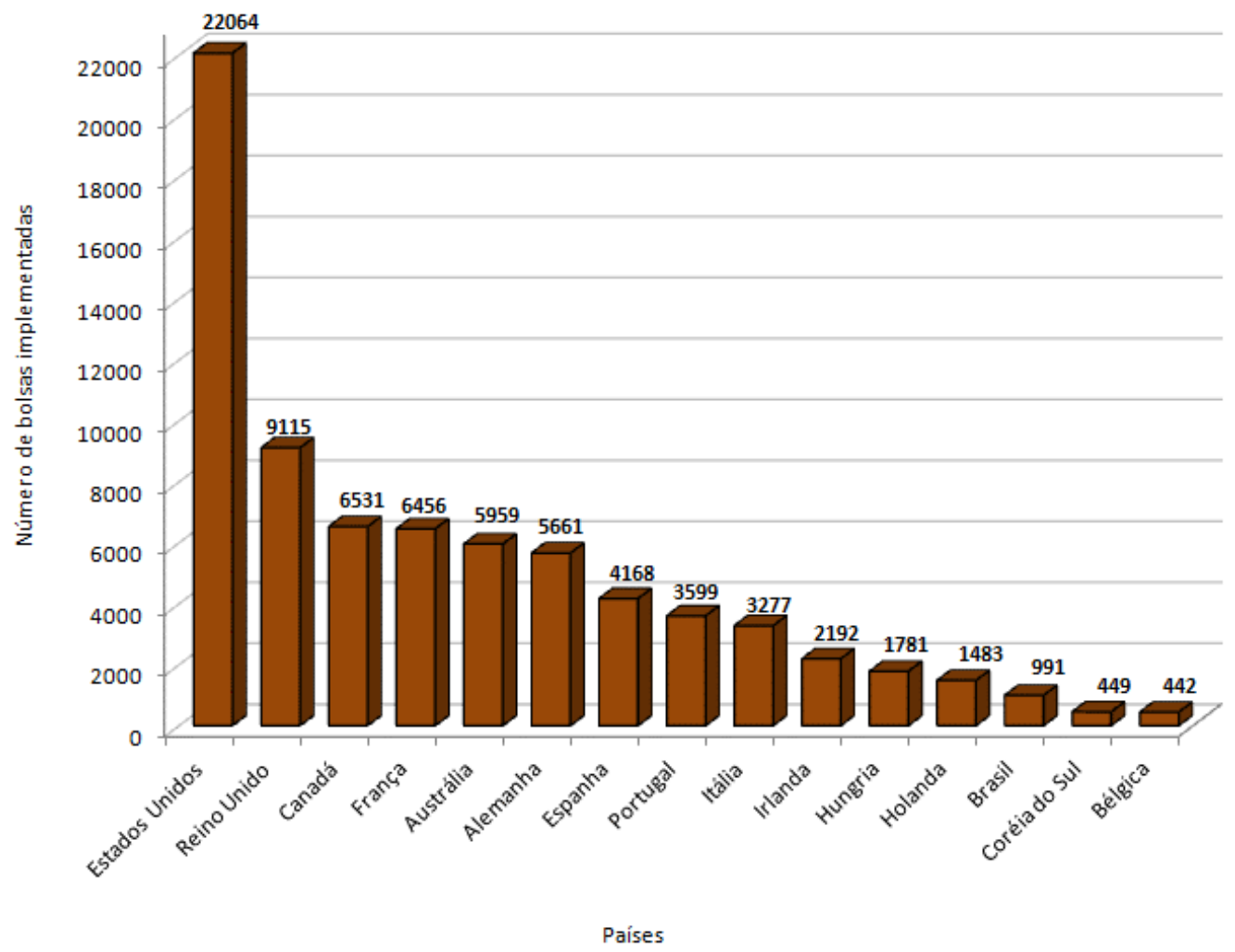

Fonte: elaboração própria a partir de dados obtidos no Programa Ciência Sem Fronteiras (2015)

\subsubsection{Publicações na Web of Science}

Os estudos sobre colaborações científicas normalmente utilizam dados referentes à contabilização de coautorias em publicações como medida quantitativa de colaboração científica. A Tabela 4 apresenta dados sobre o número de documentos em colaboração internacional e o quanto representam na produção científica do Brasil, do sistema universitário e também das universidades federais. 
O aumento da colaboração nos últimos anos é um dos fenômenos mais visíveis nos estudos da produção científica; os dados mostram que entre os anos 2003 e 2012 o número de documentos em colaboração internacional cresceu nos três âmbitos, tanto no Brasil quanto no sistema universitário e nas universidades federais. Entretanto, neste mesmo período, os valores percentuais diminuíram aproximadamente dois pontos percentuais: as publicações brasileiras em cooperação passaram de $28,17 \%$ para $26,85 \%$, as do sistema universitário de $26,08 \%$ para $25,83 \%$ e das universidades federais de $26,76 \%$ para $24,93 \%$.

Tabela 4 - Número de documentos em colaboração científica internacional e porcentagem Brasil, sistema universitário e universidades federais 2003-2012

\begin{tabular}{ccccccc}
\hline Anos & Brasil & \% & $\begin{array}{c}\text { Sistema } \\
\text { universitário }\end{array}$ & \% & $\begin{array}{c}\text { Universidades } \\
\text { federais }\end{array}$ & \% \\
\hline 2003 & 4.895 & 28,17 & 3.967 & 26,08 & 2.153 & 26,76 \\
2004 & 5.734 & 29,85 & 4.675 & 27,99 & 2.564 & 27,75 \\
2005 & 5.998 & 29,53 & 4.938 & 27,86 & 2.761 & 27,65 \\
2006 & 6.587 & 28,72 & 5.491 & 27,27 & 3.095 & 27,30 \\
2007 & 7.460 & 25,81 & 6.283 & 24,60 & 3.538 & 24,35 \\
2008 & 8.517 & 24,66 & 7.188 & 23,48 & 4.127 & 22,96 \\
2009 & 9.109 & 24,62 & 7.664 & 23,39 & 4.501 & 22,93 \\
2010 & 9.852 & 24,94 & 8.385 & 23,84 & 4.980 & 23,15 \\
2011 & 10.876 & 25,73 & 9.276 & 24,85 & 5.712 & 24,36 \\
2012 & 12.054 & 26,85 & 10.329 & 25,83 & 6.353 & 24,93 \\
Total & $\mathbf{8 1 . 0 8 2}$ & $\mathbf{2 6 , 4 2}$ & $\mathbf{6 8 . 1 9 6}$ & $\mathbf{2 5 , 1 5}$ & $\mathbf{3 9 . 7 8 4}$ & $\mathbf{2 4 , 6 8}$ \\
\hline
\end{tabular}

Fonte: elaboração própria a partir de dados obtidos na Web of Science.

Como ultimamente a colaboração científica tem sido vista como uma virtude, cada vez mais as políticas públicas a incentivam ativamente, tanto em nível individual quanto institucional. No período estudado, as universidades federais colaboraram com um total de 172 países distribuídos pelos cinco continentes do mundo e a Tabela 5 apresenta os vinte primeiros, juntamente com o número de documentos publicados e a porcentagem do quanto representam sobre a produção da WoS. 
Tabela 5 - Ranking dos vinte primeiros países, número e porcentagem de documentos publicados em colaboração internacional (WoS 2003-2012)

\begin{tabular}{cccc}
\hline Ranking & País & Número de documentos & $\mathbf{\%}$ \\
\hline $1^{\circ}$ & Estados Unidos & 14.934 & 37,54 \\
$2^{\circ}$ & Reino Unido & 5.311 & 13,35 \\
$3^{\circ}$ & França & 5.202 & 13,08 \\
$4^{\circ}$ & Alemanha & 4.681 & 11,77 \\
$5^{\circ}$ & Espanha & 3.764 & 9,46 \\
$6^{\circ}$ & Canadá & 2.975 & 7,48 \\
$7^{\circ}$ & Itália & 2.911 & 7,32 \\
$8^{\circ}$ & Argentina & 2.605 & 6,55 \\
$9^{\circ}$ & Portugal & 2.587 & 6,50 \\
$10^{\circ}$ & Austrália & 1.731 & 4,35 \\
$11^{\circ}$ & Holanda & 1.623 & 4,08 \\
$12^{\circ}$ & Suíça & 1.617 & 4,06 \\
$13^{\circ}$ & China & 1.329 & 3,34 \\
$14^{\circ}$ & Rússia & 1.310 & 3,29 \\
$15^{\circ}$ & Colômbia & 1.270 & 3,19 \\
$16^{\circ}$ & México & 1.260 & 3,17 \\
$17^{\circ}$ & Japão & 1.246 & 3,13 \\
$18^{\circ}$ & Chile & 1.195 & 3,00 \\
$19^{\circ}$ & Suécia & 1.142 & 2,87 \\
$20^{\circ}$ & Bélgica & 1.092 & 2,74 \\
\hline
\end{tabular}

Fonte: Elaboração própria a partir de dados obtidos na Web of Science.

Nas universidades públicas federais brasileiras, a colaboração internacional se dá principalmente com quatro tradicionais países parceiros: os Estados Unidos $(37,54 \%)$, o Reino Unido $(13,35 \%)$ a França $(13,08 \%)$ e a Alemanha, com $11,77 \%$ dos documentos publicados em colaboração (Figura 10). 
Figura 10 - Representação gráfica dos países com os quais as universidades federais brasileiras colaboram científica e internacionalmente

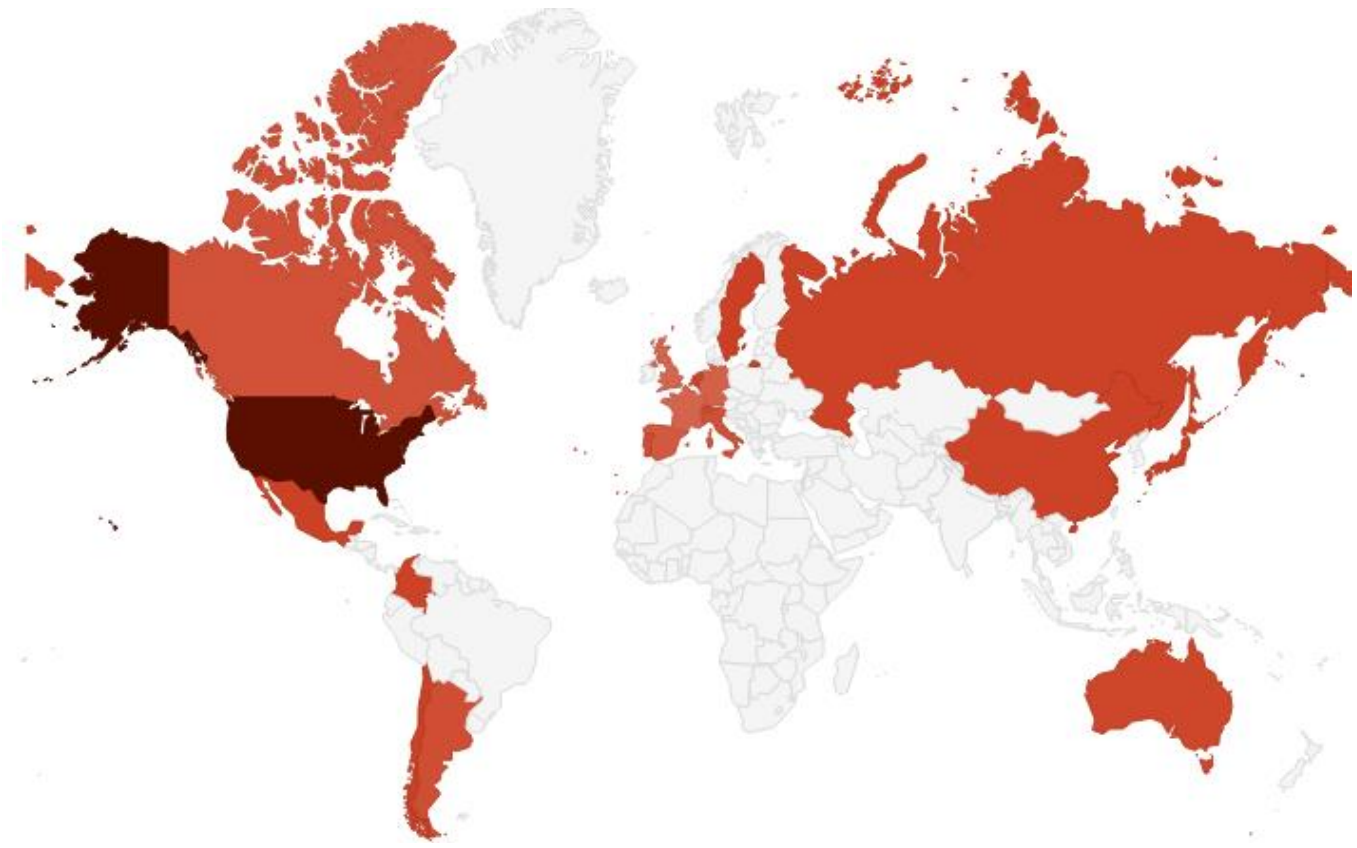

Fonte: elaboração própria a partir de dados obtidos na Web of Science.

\section{Considerações finais}

As exigências impostas pela globalização traduziram-se, ao longo das últimas décadas, em mudanças no sistema universitário público brasileiro. Este trabalho teve o objetivo de propor uma série de ferramentas que permitissem analisar o impacto "objetivo" do Programa REUNI em relação a determinados âmbitos da atividade investigativa. Neste sentido, a análise bibliográfica mostrou que a sua implantação pelas universidades federais se deu em meio a uma série de controvérsias entre os setores governamentais que o promoveram e os diferentes setores da comunidade universitária atores do âmbito universitário (SILVA, 2014), e que já existe uma vasta literatura que vem debatendo os limites, possibilidades, ganhos e perversões do REUNI (ZAMBELLO, 2013).

Devido às polêmicas geradas pelo Programa, decidiu-se utilizar indicadores quantitativos como medida de aproximação ao estudo do impacto. $\mathrm{Na}$ primeira dimensão analisada, o crescimento, considerou-se o aumento de professores como um bom indicador de desenvolvimento do sistema universitário, uma vez que a contratação de novos docentes se configura como uma das prin- 
cipais demandas do Programa REUNI para tornar possível o cumprimento de suas metas estratégicas. Este contingente adicional de profissionais seria essencial para os novos cursos na formação de professores para a Educação Básica e para ampliar a oferta na pós-graduação (BRASIL, 2015). Constatou-se que,nas universidades federais, houve um grande aumento no número de docentes efetivos, principalmente com titulação de doutor, e esse crescimento pode ser compreendido como uma estratégia para qualificar o ensino na educação superior, uma vez que a contratação de professores doutores efetivos garante a constituição de um coletivo mais compromissado com o ensino, a pesquisa e a extensão (BRASIL, 2015).

Essas informações apontam para um aspecto importante, segundo Borsoi (2012, p. 82): em maior ou menor grau, houve significativa elevação da demanda de trabalho docente, exatamente aquele que assume as incumbências da pósgraduação, tendo, por isso, a obrigatoriedade de manter elevada a produção científica das universidades. Justamente, parece ser que tal aumento não foi proporcional ao do número de vagas para os discentes. Fadul, Bleicher e Jesus (2013) observam que entre os anos de 2008 e 2012 houve um crescimento de 65,5\% do número de vagas ofertadas em cursos de graduação presenciais, enquanto no mesmo período verificou-se um aumento de $26,3 \%$ dos docentes.

Para analisar o impacto que esse incremento teve no número de professores, examinou-se a evolução da produção científica na base de dados WoS. Ainda que as publicações da ciência dominante representem somente uma parte da produção total de um país, seu uso está generalizado, uma vez que os artigos captam os conhecimentos no momento preciso de sua divulgação, mantendo-se muito próximos à ciência que está em pleno processo de elaboração (CALLON et al., 1995).Neste sentido, distintos autores têm destacado que a atividade investigativa desenvolvida pelas universidades em todo o mundo vem ganhando cada vez mais relevância, sendo possível constatar numerosos estudos que analisam resultados de input e ouput neste setor (DARAIO et al.,2011; BONACCORSI, 2014). 
No caso do Brasil, observou-se que as universidades federais foram as instituições que mais aumentaram a produção, alcançando um crescimento interanual de $13,87 \%$. Algumas delas não foram tão produtivas, entretanto tiveram um importante incremento no volume total de seus documentos. Não obstante,ainda segundo Borsoi (2012), tal aumento tem também outra face: o esforço de pesquisadores das universidades federais em investigar, socializar seus estudos e dar visibilidade às universidades públicas, em um quadro de intensificação do trabalho docente, inclusive com a política de metas produtivista criada por instituições que financiam e/ou controlam parte do trabalho acadêmico.

Para a análise da segunda dimensão, a qualidade, tomou-se como indicador a porcentagem de professores doutores das universidades federais brasileiras, haja visto que o doutorado é o máximo grau acadêmico do sistema educativo e constitui-se como principal porta de ingresso para o mundo científicoacadêmico. Desde que foi implementado em Bolonha em 1219, seu significado foi variando ao longo dos séculos (KOERNER; MAHONEY, 2005)e atualmente representa a capacidade investigativa com que uma instituição conta. Os dados obtidos neste estudo mostram que, entre os anos 2003 e 2012, houve um relevante crescimento no número de professores doutores seguido respectivamente pela redução gradual dos docentes somente graduados, especialistas e mestres.

Em paralelo, sobre a qualidade das publicações científicas entre os anos 2003 e 2012, verificou-se o aumento do número de documentos em Q1, porém não tanto como se esperava. Como a dinâmica de publicar em revistas internacionais de alto prestígio é relativamente nova no Brasil (POBLACIÓN et al., 2011), discutir medidas para promover e recompensar a qualidade - e não somente a quantidade - da produção científica é uma atividade ainda muito recente, que merece atenção e ainda tem um longo caminho a percorrer.

A terceira dimensão, a internacionalização, tem uma importância central no contexto atual da globalização da atividade científica. A mobilidade acadêmica é um dos principais referentes dos processos e das estratégias de cooperação educativa e, além de ser expressão direta da colaboração entre instituições e estruturas governamentais, também se constitui como elemento importante do 


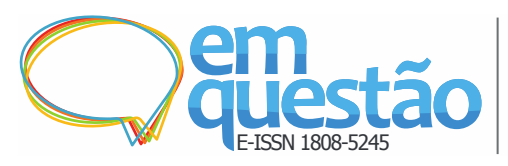

Impacto do Programa de Apoio a Planos de

Reestruturação e Expansão das Universidades Federais

(REUNI) na atividade investigativa: crescimento,

qualidade e internacionalização

Cláudia Daniele de Souza, Daniela De Filippo e Elías Sanz Casado

conjunto de políticas educativas em matéria de internacionalização da educação superior e da colaboração em matéria de desenvolvimento (GARCÍA PALMA, 2013). Com relação à internacionalização das universidades federais brasileiras,a mobilidade acadêmica e a colaboração internacional são elementos chave (CANTO, 2005).Neste sentido, desde a implementação do Programa Ciência Sem Fronteiras, a abertura do Brasil ao mundo tem sido muito relevante.

Diversos estudos têm analisado a relação entre a mobilidade e a colaboração internacional, detectando que a realização de estágios em centros estrangeiros incrementa a publicação de documentos em colaboração (KYVIK; LARSEN, 1994; BARJAK, ROBINSON, 2007; DE FILIPPO et al., 2009). No caso do Brasil, foi possível comprovar que a produção científica em colaboração internacional também cresceu significativamente na última década, tanto em volume de documentos, quanto em número de países parceiros. Concentrada principalmente na pós-graduação (MOROSINI, 2011), entre grupos, centros, núcleos de pesquisa e rede de pesquisadores, tanto no âmbito discente como no docente, à medida que sucede com países de maior expressão no cenário científico mundial, mais aumentam as oportunidades de divulgação de suas pesquisas em periódicos de projeção mundial e de aperfeiçoamento em suas especialidades, favorecendo, inclusive, posteriores buscas por financiamentos (SANTOS, 2015).

Além dos tradicionais países parceiros, nos últimos anos a colaboração científica cresceu rapidamente com a Europa, especialmente com Portugal e Espanha, que por razões históricas mantêm forte ligação, polarizam a colaboração com os países latino-americanos e apresentam taxas significativas de colaboração (LEYDESDORFF et al., 2013).

Todos estes resultados evidenciam que o Brasil, o sistema universitário e, especialmente, as universidades federais vêm esforçando-se consideravelmente a favor da melhoria e de sua atualização, que está começando a dar frutos. A expansão do sistema universitário e sua entrada na comunidade internacional já foram atingidas, no entanto ainda se fazem necessários mais alguns passos para 


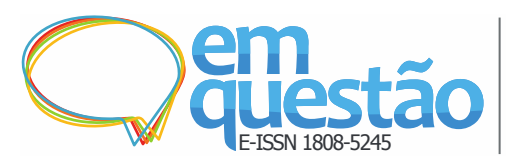

Impacto do Programa de Apoio a Planos de Reestruturação e Expansão das Universidades Federais (REUNI) na atividade investigativa: crescimento, qualidade e internacionalização Cláudia Daniele de Souza, Daniela De Filippo e Elías Sanz Casado

conseguir alcançar significativa repercussão internacional e, assim, aumentar a qualidade científica, o que sem dúvida será conquistado nos próximos anos.

\section{Referências}

ARAÚJO, C. B.; SANTOS, L. M. M. The REUNI in the perspective of the public university's managers.Psicologia\&Sociedade, Belo Horizonte, v. 26, n. 3, p. 642-651, dez. 2014.

ARAÚJO, M. A. D. DE; PINHEIRO, H. D. State management reform and reverberation on the educational system: an assessment of REUNI. Ensaio: avaliação e políticas públicas em educação, Rio de Janeiro, v. 18, n. 69, p. 647668, dez. 2010.

BARJAK, F.; ROBINSON, S. International collaboration, mobilityandteam diversityin thelife sciences: impacton researchperformance. Social Geography Discussions, v.3, p. 121-157, 2007.

BONACCORSI, A. (Ed.). Knowledge, diversity and performance in European Higher education:a changing landscape. Massachusetts: Edward Elgar, 2014.

BORGES, M. C.; AQUINO, O. F. Educação Superior no Brasil e as políticas de expansão de vagas do Reuni: avanços e controvérsias. Educação Teoria e Prática, Rio Claro, v. 22, p. 117-138, 2012.

BORSOI, I. C. F. Trabalho e produtivismo: saúde e modo de vida de docentes de instituições públicas de Ensino Superior. Cadernos de Psicologia Social do Trabalho, São Paulo, v. 15, n. 1, p. 81-100, 2012.

BRASIL. Decreto ${ }^{\circ}$ 6.096, de 24 de abril de 2007. Programa de Apoio a Planos de Reestruturação e Expansão das Universidades Federais (REUNI). Diário Oficial[da]União, Brasília, DF, 25 abr. 2007.

BRASIL. Ministério da Educação. Análise sobre a expansão das universidades federais 2003 a 2012. Disponível em: <http://portal.mec.gov.br/> Acesso em: 23 set. 2015.

BRASIL. Programa Ciência sem fronteiras: Bolsistas e Investimentos.Ministérios da Ciência, Tecnologia e Inovação (MCTI); Ministério da Educação (MEC). 2015. Disponível em: <http://www.cienciasemfronteiras.gov.br/web/csf/painel-de-controle> Acesso em: 16 out 2015. 
CARVALHO, C. H. A. Política para a educação superior no governo Lula: expansão e financiamento. Revista do Instituto de Estudos Brasileiros, São Paulo, n. 58, p. 209-244, jun. 2014.

CALlON, M.; COURTIAL, J.P.; PENAN, H. Cienciometría. El estudio cuantitativo de la actividad científica: de la bibliometría a la vigilancia tecnológica. Gijón: Trea, 2005.

CASTRO, A. A.; CABRAL NETO, A. O ensino superior: a mobilidade estudantil como estratégia de internacionalização na América Latina. Revista Lusófona de Educação, Lisboa, v. 21, p. 69-96, 2012.

CANTO, I. O Brasil e a evolução da colaboração científica internacional. In: SARAIVA, J. F. S.; CERVO, A. L. (Org.). O crescimento das Relações Internacionais no Brasil. Brasília: IBRI, 2005. Cap. 3. p. 173-194.

COSTA, D. M.; COSTA, A. M.; BARBOSA, F. V. Financiamento público e expansão da educação superior federal no Brasil: o REUNI e as perspectivas para o REUNI 2. Revista Gestão Universitária na América Latina, Santa Catarina, v. 6, n. 1, p.106-127, 2013.

COLLINS, J.; HUSSEY, R. Pesquisa em Administração.Porto Alegre: Bookman, 2005.

DARAIO, C. et al. The European university landscape: A micro characterization based on evidence from the Aquameth project. Research Policy, Amsterdam, v. 40, p. 148-164, 2011.

DEFILIPPO, D., SANZ-CASADO, E., GÓMEZ, I. Quantitative and Qualitative approaches to the study of mobility and scientific performance:a case study of a Spanish university.Research Evaluation, Guildford-Inglaterra,v. 18, n. 3, set. 2009.

FADUL, I.; BLEICHER, L.; JESUS, S. C. S. Significados e sentidos do trabalho docente nas universidades federais brasileiras: das dinâmicas de precarização às práticas de resistência da desestruturação da carreira do magistério superior. In: CONGRESO LATINOAMERICANO DE SOCIOLOGÍA, 29., 2013, Santiago. Anais... Santiago, 2013. Crisis y Emergencias Sociales en América Latina, Congreso ALAS Chile, 2013.

GARCÍA PALMA, J. J. Movilidad estudiantil internacional y cooperación educativa en el nivel superior de educación. Revista Iberoamericana de Educación, Madrid, n. 61, p. 59-76, 2013.

GARFIELD, E. The impact factor. Current Contents, v. 25, n. 20, p. 3-8, jun. 1994. 


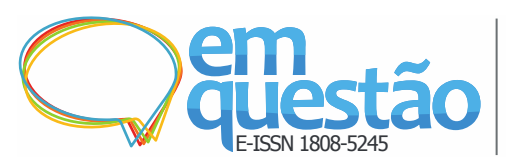

Impacto do Programa de Apoio a Planos de

Reestruturação e Expansão das Universidades Federais

(REUNI) na atividade investigativa: crescimento,

qualidade e internacionalização

Cláudia Daniele de Souza, Daniela De Filippo e Elías Sanz Casado

GREGÓRIO, J. R. B. O REUNI na UFF e os impactos no quadro de pessoal docente. Universidade e Sociedade,Maringá, jun. 2012.

KYVIK, S.; LARSEN, I. M. International contact and research performance. Scientometrics, Amsterdam, v. 29, n. 1, p. 161-172, 1994.

KOERNER, K. C.; MAHONEY, M. J. Los orígenes del Doctorado en Psicología. In: BUELA-CASAL, G. (Dir.).Manual práctico para hacer un doctorado. Madrid: Eos, 2005. p. 19-39.

LASCURAIN SÁNCHEZ, M. L. La evaluación de la actividad científica mediante indicadores bibliométricos. Bibliotecas, La Habana, v. 24, n. 1-2, p. 926, 2006.

LEYDESDORFF, L. et al. International collaboration in science: the global map and the network. El profesional de lainformación, Barcelona, v. 22, n. 1, p. 8795, 2013.

LIMA, L. C.; AZEVEDO, M. L. N.; CATANI, A. M. O processo de Bolonha, a avaliação da educação superior e algumas considerações sobre a Universidade Nova.Avaliação (Campinas), Sorocaba, v. 13, n. 1, mar. 2008.

LIMA, K. Trabalho docente e formação profissional nas universidades federais. Revista de Políticas Públicas, UFMA: São Luís, n. esp., p. 313-321, 2010.

LIMA, P. G. Políticas de educação superior no Brasil na primeira década do século XXI: alguns cenários e leituras. Avaliação: revista da avaliação da educação superior, v. 18, n. 1, p. 85-105, mar. 2013.

MANCEBO, D. et al. Políticas de expansão da educação superior no Brasil 1995-2010. Revista Brasileira de Educação, Rio de Janeiro, v. 20, n. 60, p. 3150, mar. 2015.

MICHELOTTO, R. M.; COELHO, R. H.; ZAINKO, M. A. S. The higher education enlargement policy and the proposal for higher education reform of Lula's government. Educar em Revista, Curitiba, n. 28, p. 179-198, dez. 2006.

MINISTÉRIO DA EDUCAÇÃO. Programa de apoio a planos de Reestruturação e Expansão das Universidades Federais Reuni 2008 relatório de primeiro ano. Brasília: MEC, 2009.

MOROSINI, M. C. Internacionalização na produção de conhecimento em IES Brasileiras: cooperação internacional tradicional e cooperação internacional horizontal. Educação em Revista, Belo Horizonte, v. 27, n. 1, p. 93-112, abr. 2011. 


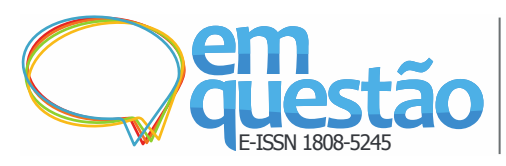

Impacto do Programa de Apoio a Planos de Reestruturação e Expansão das Universidades Federais (REUNI) na atividade investigativa: crescimento, qualidade e internacionalização Cláudia Daniele de Souza, Daniela De Filippo e Elías Sanz Casado

MUGNAINI, R.; JANNUZZI, P. M.; QUONIAM, L. Indicadores bibliométricos da produção científica brasileira: uma análise da base Pascal. Ciência da Informação, Brasília, v. 33, n. 2, p. 123-131, 2004.

POBLACIÓN, D. A. et al. (Org.). Revistas científicas: dos processos tradicionais às perspectivas alternativas de comunicação. São Paulo: Ateliê, 2011.

PRESTES, E. M.T.; JEZINE, E.; SCOCUGLIA, A. C. Democratização do Ensino Superior Brasileiro: O caso da Universidade Federal da Paraíba. Revista Lusófona de Educação, Lisboa, n. 21, p. 199-218, 2012.

REESTRUTURAÇÃO E EXPANSÃO DAS UNIVERSIDADES FEDERAIS (REUNI). O que é o REUNI. Disponível em: <http://reuni.mec.gov.br> Acesso em: 26 ago. 2015.

RISTOFF, D. O novo perfil do campus brasileiro: uma análise do perfil socioeconômico do estudante de graduação. Avaliação (Campinas), Sorocaba, v. 19, n. 3, Nov 2014.

SANTOS, B. L. P. A representação do REUNI no debate do ensino superior enquanto direito. Educação em Revista, Marília, v.10, n.1, p.29-44, jan.-jun. 2009.

SANTOS, S. M. O desempenho das universidades brasileiras nos rankings internacionais: áreas de destaque da produção científica brasileira. 2015. 342 f. Tese (Doutorado) - Escola de Comunicações e Artes, Universidade de São Paulo, São Paulo, 2015.

SGUISSARDI, V.; SILVA JUNIOR, J. R. La forma y los motivos de la expansión de la educación superior pública en Brasil. Revista de la educación superior, v. 41, n. 162, p. 67-86, jun. 2012.

SILVA, H. R. B.; ADEODATO, P. J. L. A data miningapproachforpreventingundergraduatestudentsretention. In: WORLD CONGRESS ON COMPUTATIONAL INTELLIGENCE, 2012, Brisbane. Proceedings... Brisbane, 2012.

SILVA, R. L.; FREITAS, F. C. H. P.; LINS, M. T. G. A implantação do Programa de reestruturação e expansão das universidades federais/REUNI: um estudo de caso. Revista Gestão Universitária na América Latina, Florianópolis, v. 6, n. 4, p. 147-170, 2013.

SILVA, C. O. Programa Reuni: ampliação do acesso ao ensino superior? 2014. Dissertação (Mestrado) - Programa de Pós-Graduação em Educação, Universidade Federal de Santa Catarina, Florianópolis, 2014. 
SOUSA, A. P. R.; COIMBRA, L. J. P.; SOUSA, M. S. Reforma universitária e as consequências para a qualidade da educação superior pública: o caso da Universidade Federal do Maranhão. In: JORNADA INTERNACIONAL DE POLÍTICAS PÚBLICAS, 5., 2011, São Luís. Anais...São Luís: UFMA, 2011.

STALLIVIERI, L. El sistema de educación superior de Brasil: características, tendencias y perspectivas. Universidades, n. 34, p. 47-61, mai./ago., 2007.

TONEGUTTI, C. A.; MARTINEZ, M. A universidade nova, o REUNI e a queda da universidade pública. Disponível em:

<http://www.ia.ufrrj.br/ppgea/conteudo/conteudo-2008-1/EducacaoMII/Texto\%209.pdf> Acesso em: 25 Julho 2015.

VANZ, S. A de S. As redes de colaboração científica no Brasil (2004-2006). 2009. Tese (Doutorado) - Programa de Pós-graduação em Comunicação e Informação, Universidade Federal do Rio Grande do Sul, Porto Alegre, 2009.

WESKA, A. R. O Programa Reuni na Universidade Federal de Juiz de Fora. 2012. Dissertação (Mestrado) - Programa de Mestrado Profissional em Gestão e Avaliação da Educação Pública, Faculdade de Educação, Universidade Federal de Juiz de Fora, Juiz de Fora, 2012.

ZAGO, J. O. L. A implementação do Programa Expansão (2003) e do REUNI (2007) na UFTM. 2013. 134 f. Dissertação (Mestrado) - Programa de Pós-graduação em Educação, Universidade Federal de Uberlândia, 2013.

ZAMBELLO, A. Universidades Federais Brasileiras e o Impacto Regional do Reuni. RevistaGestão\&PolíticasPúblicas, São Paulo, v. 3, n. 2, p. 246-267, 2013. 


\title{
Impact of the Program of Support for Plans of Restructuring and Expan- sion of the Federal Universities (REUNI) in the investigative activity: in- crease, quality and internationalization
}

\begin{abstract}
In the last years the Brazilian higher education system has been the object of numerous public policies and one of these is the Program of Support for Plans of Restructuring and Expansion of the Federal Universities (REUNI). The purpose of this study is to analyze its impact on the investigative activity of federal universities: increase, quality and internationalization, establishing a relationship between the results of the Program and scientific publications on the web of science. From data for the period 2003-2012 it is noted that there was a considerable increase in scientific production in Brazil and even more in federal universities. The tenure of $\mathrm{PhD}$ teachers has increased, however has not yet reflected in the quality of documents in the first quartile journals. Mobility programs helped to promote formation in different countries. In addition, the publications in international collaboration have grown rapidly, but not yet achieved outstanding percentage. While emphasizing an important transformation in the federal universities, it is necessary still to integrate efforts towards quality and international visibility.
\end{abstract}

Keywords: Bibliometric analysis. Brazilian university system. Educational policy. Federal universities. REUNI.

Recebido em 15/09/2015

Aceito em 16/12/2015

${ }^{1}$ Em 2007, ano de criação do Reuni, existiam 54 universidades federais em funcionamento. A Universidade Federal do ABC (UFABC) e a Universidade Federal do Pampa (UNIPAMPA) foram criadas, respectivamente, em 2005 e 2008, já no âmbito do REUNI com as inovações pedagógicas previstas pelo Programa.

${ }^{2}$ Dados obtidos com o acesso institucional à base de dados, na Universidade Carlos III de Madrid. Consulta realizada durante o mês de Março 2015.

${ }^{3} \mathrm{CU}=$ País, busca por países no campo direções de um registro e PY=Ano de publicação, busca no campo fonte publicada. 